Goldschmidt 2021 Abstract

https://doi.org/10.7185/gold2021.7954

\section{A ferrous wheel beneath the Antarctic Ice Sheet}

\author{
JON HAWKINGS ${ }^{1,2}$, MARK SKIDMORE ${ }^{3}$, JOHN PRISCU ${ }^{3}$, \\ ELIZABETH SHOENFELT TROEIN ${ }^{4}$, CHRISTINA DAVIS ${ }^{5}$, \\ BRENT CHRISTNER ${ }^{5}$, OK-SUN KIM ${ }^{6}$, MATTHIAS \\ SIEBER $^{7}$, TIM CONWAY ${ }^{7}$, CHRISTOPHER GARDNER $^{8}$, \\ TRISTA VICK-MAJORS ${ }^{9}$, ALEXANDER MICHAUD ${ }^{10}$, \\ MARTYN TRANTER ${ }^{11}$, LIANE G. BENNING ${ }^{2,12}$ AND \\ ROBERT SPENCER ${ }^{1}$
}

${ }^{1}$ Florida State University

${ }^{2}$ GFZ German Research Centre for Geosciences

${ }^{3}$ Montana State University

${ }^{4}$ Massachusetts Institute of Technology

${ }^{5}$ University of Florida

${ }^{6}$ Korea Polar Research Institute

${ }^{7}$ University of South Florida

${ }^{8}$ Ohio State University

${ }^{9}$ Michigan Tech University

${ }^{10}$ Bigelow Laboratory for Ocean Sciences

${ }^{11}$ Aarhus University

${ }^{12}$ Freie Universität Berlin

Presenting Author: jhawkings@fsu.edu

Iron $(\mathrm{Fe})$ is one of the most important elements for the Earth's biosphere. $\mathrm{Fe}$ is a crucial component in cellular processes (e.g., metalloenzymes) and microbial metabolic pathways (e.g., microbial $\mathrm{Fe}$ oxidation and reduction). $\mathrm{Fe}$ is also an essential micronutrient for marine phytoplankton, the primary producers of the ocean, which are responsible for around half of global photosynthesis. Despite it being the fourth most abundant element in the Earth's crust, Fe is highly insoluble, due in part to its rapid oxidation from ferrous $\left(\mathrm{Fe}^{2+}\right)$ to ferric $\left(\mathrm{Fe}^{3+}\right)$ iron, which often leads to the formation of nanoparticulate iron oxyhydroxide minerals. Its insoluble nature, particularly in oxygenated waters, means Fe limitation for primary producers is prevalent in a third of Earth's surface oceans, including areas of high biological productivity proximal to a significant volume of glacial freshwater discharge (e.g., the Southern Ocean). In these areas the concentration of bioavailable $\mathrm{Fe}$ affects the primary production, and thus the strength of the biological pump and associated carbon drawdown from the atmosphere.

The role of the subglacial discharge from the Antarctic Ice Sheet (AIS) in the global Fe cycle is still poorly understood, despite the proximity of the AIS to regions of widespread Fe limitation and its sensitivity to climatic change. We combined analyses of size fractionated $(<0.02,<0.22,<0.45 \mu \mathrm{m})$ filterable concentrations, stable $\mathrm{Fe}$ isotope ratios, selective Fe-bearing particulate phase chemical extractions, with high-resolution electron and X-ray micro-spectroscopy as well as microbiological analyses from two cleanly accessed subglacial lakes $\sim 1000$ m beneath the Antarctic Ice Sheet, to investigate the importance of the subglacial ferrous wheel. Using these data, we created a conceptual model of subglacial Fe cycling and generated initial $\mathrm{Fe}$ export estimates for AIS subglacial discharge to the coastal Southern Ocean. Our data highlight the importance of AIS subglacial ecosystems in the mobilization of large quantities of potentially bioavailable iron species. 